\title{
Deducing serum fructosamine levels from the fasting blood glucose value: a preliminary study
}

\section{H. Peiris ${ }^{1}$}

The Ceylon Journal of Medical Science 2001; 44: 25-28

\begin{abstract}
The determination of glycated serum proteins (fructosamine) has become an accepted index for assessing the metabolic situation in diabetic patients. The current study describes an alternative to measurement of fructosamine level, viz., to predict the serum fructosamine based on the glucose concentration in fasting plasma. A crosssectional prospective study was performed on 44 non-diabetic, 38 impaired glucose tolerance and 38 diabetic subjects attending clinics at Colombo South Teaching Hospital. Fasting plasma glucose and corresponding serum fructosamine concentrations were determined on all subjects. Fructosamine showed a positive linear correlation of $\mathrm{r}^{2}=0.85$ with the fasting plasma glucose concentrations. Regression equation relating to these parameters was $Y=0.8173 X-120.4655$, were $Y$ and $X$ represent the plasma glucose and fructosamine values, repectively. This prediction test formula for fructosamine is shown to be a useful index for assessing the effects of changes in diabetic management.
\end{abstract}

Key words: fructosamine, fasting plasma glucose, diabetes mellitus.

\section{Introduction}

With increasing recognition of the possible importance of strict glycaemic control for prevention or delay of diabetic complications, there is much interest in methods for monitoring therepeutic control of blood glucose concentration. Of these methods, the glycated haemoglobin $\left(\mathrm{HbA}_{1 \mathrm{c}}\right)$ which reflects the integrated blood glucose concentration over 6 - 8 weeks is being widely used in Sri Lanka.
However, recent studies have shown that fructosamine (glycated protein) can be used to differentiate between well and poorly stabilized diabetics (1). Fructosamines are stable ketoamines formed by a non-enzymatic reaction between a sugar and a protein. It has been known that a number of proteins, e.g., haemoglobin, serum proteins, membrane proteins, protein in the lens of eye etc. are glycated by a nonenzymatic reaction and forms a stable fructosamine (isoglucosamine) which depends on the glucose concentration. The glycated serum proteins form very quickly with changes in the glucose concentration than the glycated haemoglobin $\left(\mathrm{HbA}_{1 \mathrm{c}}\right)$ formed in the erythrocytes. The largest fraction, about $60-70 \%$ of glycated serum proteins, consists of albumin with a halflife in serum about 2-3 weeks (2). On account of this half-life, the fructosamine (principally glycated serum albumin) can be used to assess the metabolic control of diabetic patients over a moderately short period.

The conventional way of diagnosing glycaemia is by determination of fasting blood glucose level (FBS) by the standard glucose oxidase method, whereas the laboratory methods available for determination of serum fructosamine are relatively expensive and not freely available in most of the state hospitals. Therefore, development of a suitable method to predict the expected fructosamine level for given FBS concentrations may be of value in long-term monitoring of metabolic control of diabetic patients. This study was performed to develop a test formula to predict the serum fructosamine levels from glucose concentrations in adult subjects. 


\section{Material and Methods}

A cross-sectional prospective study was performed on 44 non-diabetics, 38 with impaired glucose tolerance (IGT) and 38 diabetic subjects attending clinics at the Colombo South Teaching Hospital. Screening of non-diabetics was based on the WHO (3) criteria, i.e., those with less than $110 \mathrm{mg} / \mathrm{dL}$ of fasting blood glucose level. Those who had values above the normal were screened by the oral glucose tolerance test (OGTT). Subjects whose 2 hour blood glucose levels were 140-190 $\mathrm{mg} / \mathrm{dL}$ after ingestion of $75 \mathrm{~g}$ of glucose (4) were identified as impaired glucose tolerance (IGT) subjects. The screening of diabetics was based on their clinical history (fasting blood sugar level of more than $140 \mathrm{mg} / \mathrm{dL}$ ) and / or a 2 hour blood glucose value greater than $200 \mathrm{mg} / \mathrm{dL}$ after $75 \mathrm{~g}$ of oral glucose (4). The reference ranges for fructosamine were compared with the glucose concentrations in fasting plasma in all subjects.

\section{Sample collection and laboratory assay}

Venous blood from each subject was collected into two sets of tubes. One set contained sodium fluoride/potassium oxalate and other set did not contain any anticoagulants. Blood collected into tubes containing anticoagulant were centrifuged immediately at $2000 \mathrm{rpm}$ for $15 \mathrm{~min}$ and plasma was assayed for glucose by the standard glucose oxidase method, whilst the blood collected into plain tubes was allowed to clot and serum was separated and stored at $-20^{\circ} \mathrm{C}$ pending the fructosamine assay. Serum fructosamine assay was performed by a colorimetric method (5).

\section{Statistical analysis}

Results were analysed using SPSS package and a regression equation was obtained to predict the expected fructosamine for a given fasting plama glucose level.

\section{Results}

The distribution of status of subjects by fasting plasma glucose concentration and corresponding serum fructosamine values are given in Table 1. Based on the reference range given for fructo- samine, i.e., value of less than $265(\mu \mathrm{mol} / \mathrm{L}$ for non-diabetics and more than $300(\mu \mathrm{mol} / \mathrm{L}$ for diabetics (2), the results revealed that serum fructosamine of all 44 non-diabetics correlated sufficiently with the normal fasting glucose levels in plasma. However, only 37 out of 38 fructosamine values among diabetics correlated sufficiently with the diabetic status of the plasma glucose level. Of the 38 IGT's only 35 subjects correlated sufficiently with the plasma glucose level.

Regression equations obtained relating to serum fructosamine and fasting blood glucose for normal, IGT and diabetic subjects are as follows;

$$
\begin{array}{ll}
\text { Normal } & Y=0.5187 \times-42.3910, \mathrm{r}^{2}=0.847 \\
\text { IGT } & Y=0.7180 \times-92.9554, \mathrm{r}^{2}=0.859 \\
\text { Diabetic } & Y=1.1266 \mathrm{X}-175.783, \mathrm{r}^{2}=0.861,
\end{array}
$$

where $X$ and $Y$ represents serum fructosamine and plasma glucose values respectively. As there were no significant differences between any two of the above correlation coefficients, the data were pooled and a common regression equation was derived to deduce the serum fructosamine levels from the fasting blood glucose value.

The common regression equation relating to these parameters was $Y=0.8173 X-102.47$ where, the $Y$ and $X$ represents the fasting plasma glucose and serum fructosamine concentrations respectively. The correlation coefficient was 0.85 . This suggests that there is a clear linear association between these two parameters.

\section{Discussion and Conclusion}

The WHO estimates that the number of people with diabetes in developing countries is expected to increase to more than 65 million by $2000 / 2001$ (6). Diabetes mellitus is responsible for considerable mortality and morbidity from microvascular diseases, hyperlipidaemia, retinopathy, nephropathy and neuropathy. A genetic predisposition to develop complications as well as exposure to long term asymptomatic hyperglycaemia due to poor access to adequate health care, may contribute to the high incidence of complications (7). 
Table 1

Distribution of status of patients by plasma glucose and serum fructosamine levels

\begin{tabular}{|c|c|c|c|c|c|c|}
\hline \multirow[b]{3}{*}{$\begin{array}{l}\text { Plasma glucose } \\
\text { (mg/dL) }\end{array}$} & \multicolumn{6}{|c|}{ Serum fructosamine $(\mu \mathrm{mol} / \mathrm{L})$} \\
\hline & \multicolumn{2}{|c|}{ Normal $(\leq 264)$} & \multicolumn{2}{|c|}{ IGT (265-295) } & \multicolumn{2}{|c|}{ Diabetic $(\geq 300)$} \\
\hline & Number & $\%$ & Number & $\%$ & Number & $\%$ \\
\hline Fasting & & & & & & \\
\hline Less than 110 & 42 & 100.0 & - & - & - & - \\
\hline $\begin{array}{l}111-139 \\
\text { (140-190 at } 2 \text { hours) }\end{array}$ & - & - & 35 & 91.1 & 3 & 7.5 \\
\hline $\begin{array}{l}\text { More than } 140 \\
\text { (More than } 200 \text { at } \\
2 \text { hours) }\end{array}$ & - & - & 3 & 7.9 & 37 & 92.5 \\
\hline Total & 42 & 100.0 & 38 & 100.0 & 40 & 100.0 \\
\hline
\end{tabular}

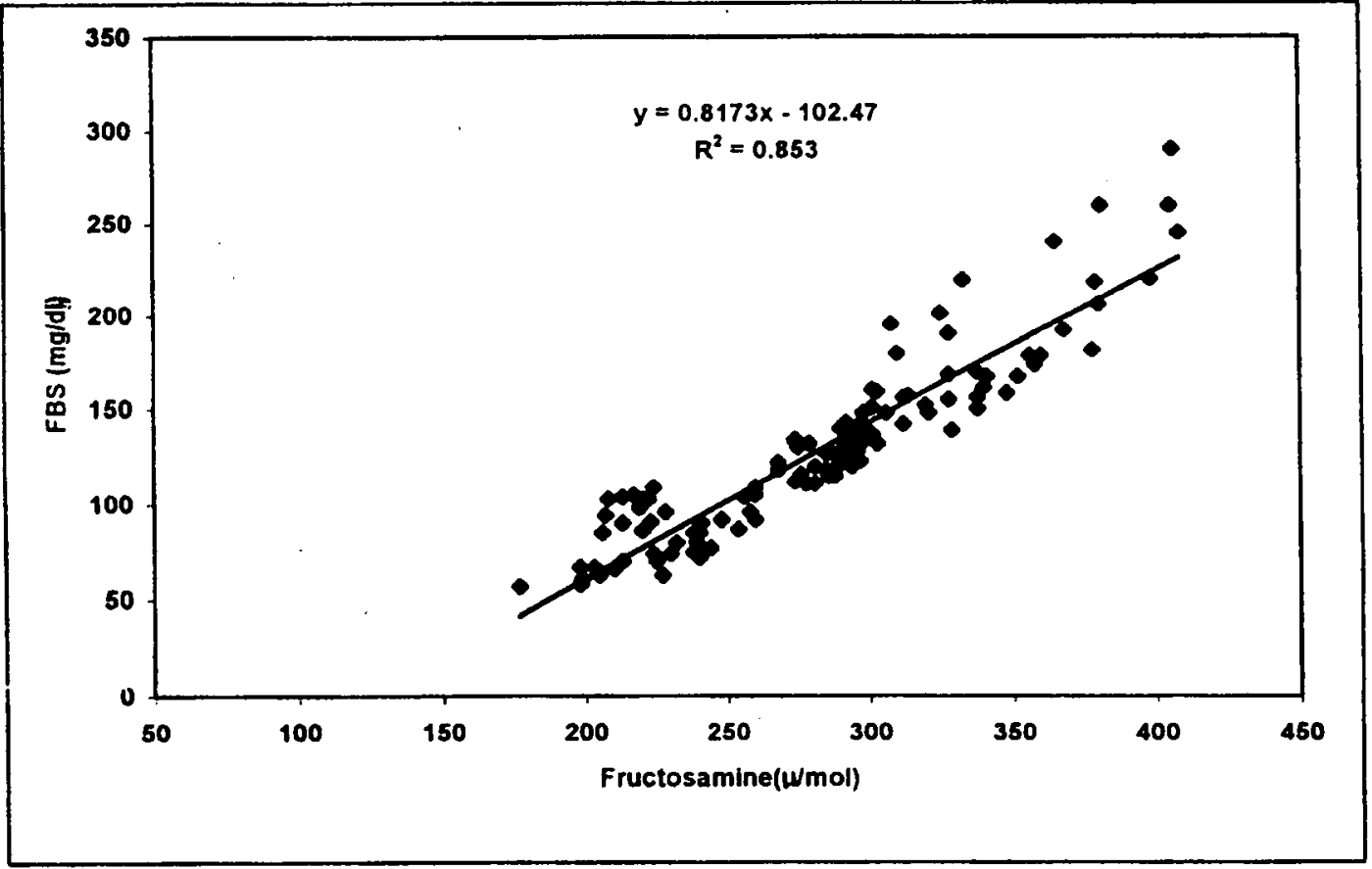

Figure 1: Relationship between Fasting Blood glucose and Fructosamine 
IGT is an intermediate state between normal and diabetic status and is an unstable state in that perhaps $30 \%$ may revert back to normal or progress to non-insulin-dependent diabetes mellitus (4). In NIDDM patients, glycaemic control may be assessed by testing the fasting blood glucose or post prandial blood glucose at regular intervals. Long term complications can occur with the blood glucose concentration from 110-180 $\mathrm{mg} / \mathrm{dL}$ (4). These complications can be minimized by early detection of the status of glycaemia.

As indicators for retrospective assessment of the metabolic situation, the glycosylated haemoglobin $\left(\mathrm{HbA}_{1 \mathrm{c}}\right)$ provides information about glycaemic control during the preceding 6-8 weeks. On account of the much shorter half life (2-3 weeks), fructosamine provides an alternative to $\mathrm{HbA}_{\mathrm{lc}}$ for monitoring the metabolic control of diabetic patients.

The serum fructosamine levels of normal, IGT and diabetic subjects in the present study correlated sufficiently with the plasma glucose control as evidenced by the positive linear correlation with the fasting plasma glucose concentration. Therefore, the suggested frutosamine prediction formula, i.e., $\mathrm{Y}=0.8173 \mathrm{X}-102.4655$, provides a useful index for assessing the glycaemic status (Figure 1). As this prediction formula is based on the fasting plasma glucose, it could be used as an initial bedside method in hospitals for monitoring glycaemic control of patients.

\section{References}

1. Baker J.R. O'Connor H.P., Metcalf P.A, Johnson R.N. Clinical usefulness of estimating of serum fructosamine concentration as a screening test for diabetes mellitus. British Journal of Medicine 1983; 287: 863-867.

2. Hentichs H.R. Methods for determination of fructosamine. In Proceedings of the European fructosamine workshop, Vienna. $26^{\text {th }}-28^{\text {th }}$ October 1989.

3. WHO Expert Committee on Diabetes mellitus. Geneva: World Health Organization Technical Report series No. 646, 1980.

4. Fernando D. Management of non-insulin dependent diabetes mellitus. Sri Lanka Prescriber 1994; 2: 1-5.

5. Jonson R.N., Metcalf P.A., Baker J.R. A new approach to estimation of serum glycosyl protein, An index of diabetic control. Clinica Chemica Acta 1982; 127: 87-95.

6. WHO Division of non-communicable diseases and health technology. Guidelines for the developement of a national programme for diabetes mellitus WHO/DBO/DM/91/1. Geneva: World Health Organization, 1991.

7. Weerasuriya N., Siribaddana S., Dissanayake A., Subasinghe Z., Wariyapola D., Fernando, D.S.J. Long-term complications in newly diagnosed Sri Lankan patients with type 2 diabetes mellitus. Queensland Journal of Medicine, 1998; 91: 439-443. 